\title{
EFEITO DO ENRIQUECIMENTO AMBIENTAL INANIMADO SOBRE O COMPORTAMENTO DE CÃES DE CANIL EM ENSAIO METABÓLICO
}

(Effect of inanimate environmental enrichment on the behavior of kennel dogs in metabolic test)

\author{
Juliana Comin¹, Juliana Regina da Silva, Larissa Wunsche Risolia, Simone Gisele \\ de Oliveira, Ananda Portella Félix, Alex Maiorka
}

${ }^{1}$ Correspondência: juliana_zoot@yahoo.com.br

RESUMO: Este estudo teve como objetivo de avaliar o efeito do enriquecimento ambiental inanimado sobre o comportamento de cães de canil alojados em gaiolas de metabolismo. O experimento foi composto por dois períodos de avaliação de 48 horas cada, com observações em intervalos de 10 minutos. Os métodos de enriquecimento testados foram a inclusão de uma bolinha de plástico presa na parte superior da gaiola e o estímulo sonoro por meio de música ambiental no local onde das gaiolas. Foram utilizados oito cães da raça Beagle adultos, sendo quatro machos e quatro fêmeas. $O$ delineamento foi inteiramente casualizado, com oito repetições no teste com música e quatro repetições no teste com a bolinha. No teste com a inclusão da bolinha, os animais não diferiram seu comportamento quanto ao tempo em ócio em pé, ócio sentado, ócio deitado, dormindo e comendo. Porém observou-se que os animais mantidos em gaiola com brinquedo passaram mais tempo se higienizando, que pode significar estado de relaxamento, conforto e cuidado normal com a pelagem. No período com música os animais passaram a maior parte do tempo dormindo e em ócio. As frequências das variáveis comportamentais foram testadas a $5 \%$ e $1 \%$ de probabilidade.

Palavras-chave: Beagle; bolinha; música; ócio

\begin{abstract}
This study aimed to evaluate the effects of inanimate environmental enrichment on the behavior of shelter dogs housed in metabolism cages. The experiment consisted of two assessment periods of 48 hours each, with observations at intervals of 10 minutes. The enrichment methods tested were the inclusion of a plastic ball attached at the top of the cage and the sound stimulus by means of ambient music in the place where the cages. Beagle dogs were used and eight adults, four males and four females. In the test with the inclusion of the ball, the animals did not differ as to their behavior in leisure time standing, sitting idle, idleness, lying, sleeping and eating. But it was observed that animals kept in a cage with toys sanitized spent more time, which may mean a state of relaxation, comfort and care to normal coat. During music animals spent most of their time sleeping and resting.
\end{abstract}

Key Words: beagle; ball, music, idleness 


\section{INTRODUÇÃO}

Os estudos na área de comportamento animal se constituem em importante campo científico de suporte para outras disciplinas, para o manejo com o meio ambiente e estudos de bem-estar (Sowdon, 1999). Cães de canil requerem, além de contato com humanos para promover seu bem-estar, estimulação através de enriquecimento ambiental inanimado (enriquecimento provido de brinquedos, acessórios, estimulação auditiva e olfativa) (Wells, 2004).

Os brinquedos são o tipo de enriquecimento ambiental inanimado mais utilizado tanto para animais domésticos quanto exóticos para estimular a descontração e diminuição do tédio e aborrecimento (Wells, 2004).

O reconhecimento dos benefícios da música para o bem-estar humano elevou o valor das pesquisas acerca do uso de estimulação auditiva como meio de enriquecimento ambiental de animais em cativeiro (Wells, 2004). A importância do enriquecimento ambiental por meio de estímulo sonoro vem sendo estudado em diferentes espécies, como pássaros (Reed et al.,1993), bovinos (Uetake et al., 1997) e cavalos (Houpt et al., 2000). Esses estudos relatam mudanças no comportamento e na fisiologia dos animais expostos a gravações musicais, estações de rádios e sons da natureza, sendo que cães de canil também reagem a estímulos sonoros (Wells, 2004).

A partir destes conceitos foi desenvolvido o presente estudo, objetivando avaliar o comportamento de cães sob a influência de dois métodos de enriquecimento ambiental inanimado: música e brinquedo.

\section{MATERIAL E MÉTODOS}

$\mathrm{O}$ experimento contou com dois períodos de 48 horas ininterruptas de análise cada, com observações realizadas em intervalos de 10 minutos, resultando 288 observações por animal em cada período. Os métodos de enriquecimento ambiental testados foram: inclusão de uma bolinha colorida de plástico, presa na parte superior da gaiola de quatro dos oito animais em estudo e estimulo sonoro pela introdução de música ambiente no local onde permaneceram as gaiolas metabólicas.

Foram utilizados oito cães da raça Beagle, com 18 meses de idade, pesando entre 8,8 e 10,2 kg. As variáveis comportamentais observadas foram: ócio em pé (OP), ócio sentado (OS), ócio deitado (OD), dormindo (D), comendo $(\mathrm{C})$, bebendo água $(A)$, se higienizando $(\mathrm{H})$, urinando $(\mathrm{U})$, defecando (DF), latindo (L), latindo $\mathrm{e}$ chorando (LC), socializando (S), brincando (BC) e comportamento estereotipado (CE).

No primeiro período foi considerado o tratamento inclusão ou não do brinquedo na gaiola, sendo utilizadas quatro repetições por tratamento. O brinquedo introduzido foi uma bolinha de plástico, presa na parte superior da gaiola de quatro dos oito cães em estudo.

No segundo período, o tratamento avaliado foi a influência do estímulo sonoro por meio de música ambiental, totalizando oito repetições por tratamento. A música era oriunda de uma estação de rádio local da cidade de Curitiba, PR, cuja programação musical é composta por músicas do estilo lounge (que promovem relaxamento). $\mathrm{O}$ aparelho sonoro colocado no canil era mantido sempre em volume baixo, mas que fosse possível ser ouvido em todos os cantos da sala onde os cães estavam mantidos. Este período foi subdivido em dois momentos, sendo que inicialmente todos os animais recebiam estimulo sonoro e posteriormente o aparelho de som foi retirado do espaço experimental 
para garantir que os animais permanecessem todo o tempo sem nenhum tipo de estimulo sonoro.

O delineamento foi inteiramente casualizado, com quatro repetições no teste com o brinquedo e oito repetições no teste com música. As frequências das observações foram analisadas pelo teste Kruskal-Wallis a $5 \%$ e $1 \%$ de probabilidade.

\section{RESULTADOS E DISCUSSÃO}

$\mathrm{Na}$ Figura 1 encontram-se descritas as frequências das observações resultantes das 48 horas de análise do enriquecimento ambiental inanimado por meio de brinquedo.

Figura 1 -

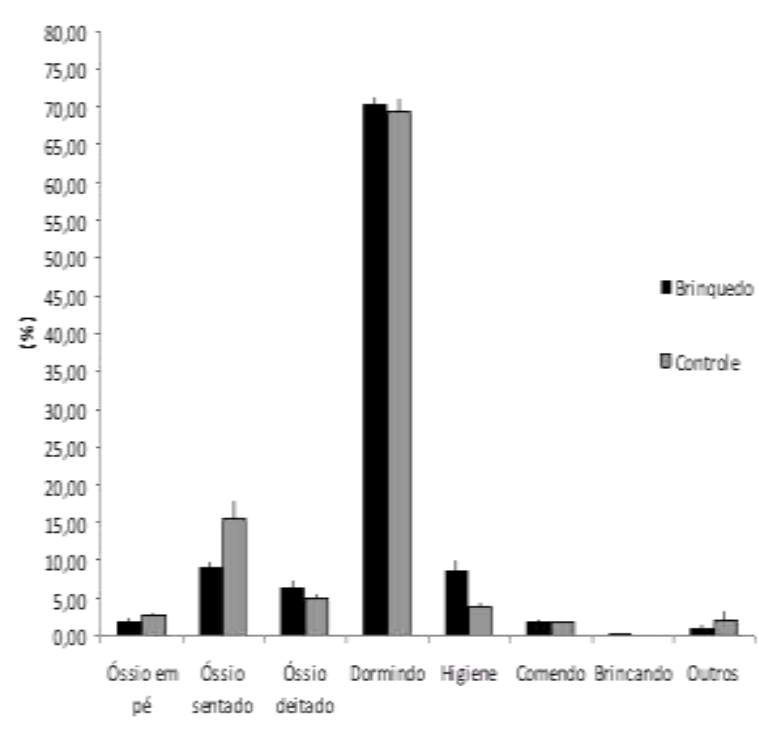

${ }^{*} \mathrm{P}<0.05$ pelo teste Kruskal-Wallis

Outros: Refere-se a soma da frequência dos demais comportamentos expressos menos que $1 \%$ do tempo.

Figura 1 - Frequência observada do comportamento de cães Beagle alojados em gaiolas contendo ou não brinquedo durante 48 horas $(n=8)$.

Os cães passaram apenas $0,22 \%$ $\pm 0,07$ do tempo interagindo com a bolinha em relação aos cães mantidos em gaiola controle $(P=0,02)$. Os animais passaram a maior parte do tempo dormindo, o que sugere a ausência ou quase inexistência de estresse, mesmo em condições não naturais, como a permanência em gaiolas de metabolismo. Cunha et. al. (2007) trabalhando com bezerros mestiços mantidos em diferentes tipos de abrigos, também relataram que os animais passaram a mais da metade do tempo em ócio deitado ou dormindo, mostrando total conforto e interação positiva com o meio.

Porém, a presença da bolinha não fez com que o comportamento dos animais não se alterasse em comparação aqueles que não tinham nenhum tipo de estimulo visual na gaiola. O único comportamento que se mostrou mais freqüente nos animais que possuíam a bolinha em sua gaiola, foi o de se higienizar. Segundo Horwitz \& Neilson (2008) o ato de se higienizar, de lamber-se é uma comportamento normal dos cães, que expressa cuidado com a pelagem e é muitas vezes utilizado como fator apaziguador entre os cães. Portanto, podemos concluir que a presença de bolinha ainda que de forma branda, estimulou o relaxamento e o bem-estar dos cães.

DeLuca \& Kranda (1992) relatam em seu estudo que cães adultos se habituam rapidamente a brinquedos e demonstram interesse renovado pela introdução de estimulo completamente novo e diferente. Wells (2004) sugere que a rotação de brinquedos pode ser mais interessante que sua simples inclusão quando se trata de animais de canil.

$\mathrm{Na}$ Figura 2 encontram-se descritas as frequências das observações resultantes das 48 horas de análise do enriquecimento ambiental promovido por meio de estimulo sonoro (música). 


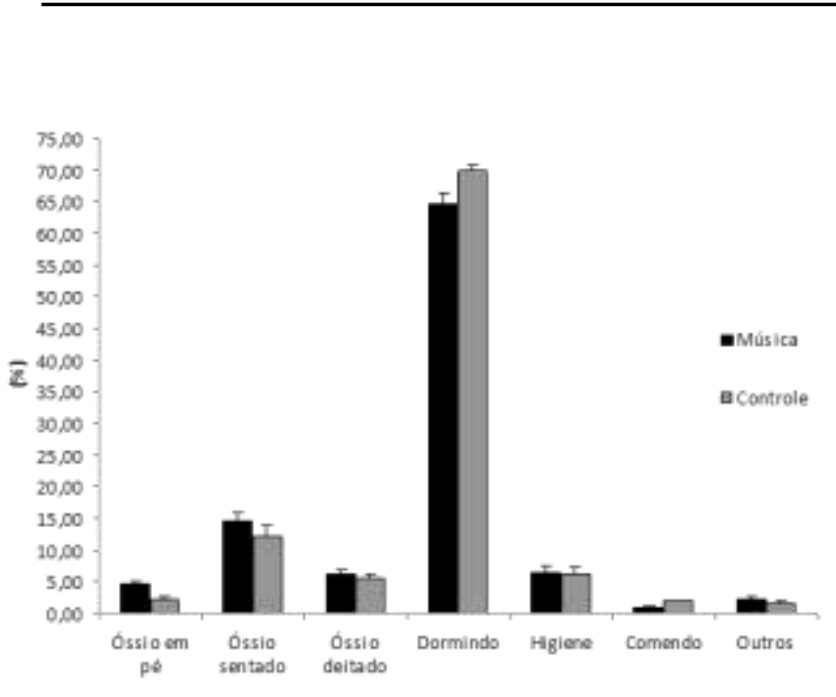

${ }^{*} \mathrm{P}<0.01$ pelo teste Kruskal-Wallis

Outros: Refere-se a soma da frequência dos demais comportamentos expressos menos que $1 \%$ do tempo.

Figura 2 - Frequência observada do comportamento de cães Beagle alojados em gaiolas metabólicas recebendo ou não estímulo sonoro (música).

Os animais passaram a mais de $60 \%$ do tempo dormindo em ambos os períodos, que sugere a ausência de estresse, mesmo em condições consideradas pelos humanos como desconfortáveis. Também é possível observar sobre o tempo que eles passaram dormindo, que este foi maior no período controle. Isso pode ser explicado pelo fato de a música usada como estímulo sonoro ser proveniente de uma estação de rádio, e apesar do estilo de música ser padrão, havia momentos de comercias, onde os sons eram de diferentes tipos e intensidade. Mesmo mantendo o volume do aparelho sonoro baixo, foi possível perceber que durante os intervalos comerciais, os cães acordavam e se agitavam um pouco, o que contribui para a diminuição da porcentagem de tempo dormindo dos mesmos.

O tipo de som a que os animais são expostos influenciam de maneira diferente a manifestação de seus comportamentos. Wells (2004) relatou que cães alojados em abrigos passaram bastante tempo demonstrando comportamento sugestivo de relaxamento (reduzindo os latidos $e$ aumentando o tempo em descanso) quando expostos a música clássica, ao passo que quando expostos a rock pesado, passaram a maior parte do tempo demonstrando comportamentos sugestivos de agitação (latidos excessivos).

Outro ponto importante é que no período com música, os animais passaram mais tempo em ócio, que segundo Wells (2004) é comportamento sugestivo de relaxamento. Portanto é possível concluir que a música promove bem-estar de cães canil submetidos a ensaios de digestibilidade, porém é preciso levar em conta o tipo e a uniformidade do efeito sonoro utilizado como estímulo para enriquecimento ambiental.

Outro estudo realizado por Woodford (2004) demonstrou que cães que estavam expostos a canções de ninar (lulabies) diminuíram a ansiedade, latidos e choros. Conforme Grinde (2000), a música tem efeito relaxante, não somente em humanos, mas também em animais. $O$ efeito relaxante é explicado possivelmente por a música ser contínua e rítmica. Em ambiente natural, o perigo pode ser acompanhado por sons repentinos e inesperados. Sons constantes sugerem condições de paz, enquanto descontínuos exigem atenção, o que pode ter sido a causa do agito quando os cães escutavam a propaganda da rádio. O som contínuo que é considerado seguro relaxa o cérebro.

Para Reinecker (2014), a música tem sido usada para aliviar o estresse e melhorar o bem estar. Verifica-se que a música clássica traz benefícios de cura para os cães. Eles passam mais tempo em estado relaxado quando expostos à música clássica, descansam mais, latem menos, e ficam mais calmos quando chegam visitas. 


\section{CONCLUSÃO}

Os dois métodos de enriquecimento ambiental testados promovem bem-estar e relaxamento em cães da raça Beagle de canil submetidos a condições de ensaio de metabolismo.

\section{NOTAS INFORMATIVAS}

Aprovado CEUA do Setor de Ciências Agrárias da UFPR protocolo No. 024/2015, em 22/04/2015.

\section{REFERÊNCIAS}

CUNHA, D.N.F.V.; CAMPOS, O.F.; PEREIRA, J.C et al. Desempenho, variáveis fisiológicas e comportamento de bezerros mantidos em diferentes instalações: época chuvosa. Revista Brasileira de Zootecnia, v.36, n.4, p. 1140-1146, 2007.

DELUCA,A.M.;KRANDA,K.C. Environmental enrichment in a large animal facility. Laboratory Animal, n.21, p.38-44,1992.

HORWITZ, D.F. \& NEILSON, J.C. Comportamento canino e felino. Tradução José Sérgio C. de Azevedo. Porto Alegre: Artimed, 2008. $662 \mathrm{p}$.

HOUPT, K.; MARROW,M.; SEELIEGER,M. A preliminary study of the effect of music on equine behavior. Journal of Veterinary Equine Science, n. 20, p. 691-737, 2000.

REED,H.J.; WILKINS,L.J.; AUSTIN,S.D. et al. The effect of environmental enrichment during rearing on fear reactions and depopulation trauma in adult caged hens. Applied Animal Behaviour Science, n.36, p. 39-46, 1993.

REINECKER, D. Music for dogs. Disponível em: <http://www.learningdog.com/musicfordogs.html > Acesso em: 15/01/2014.

SNOWDON, C.T. O significado da pesquisa em Comportamento Animal. Estudos de Psicologia, n. 4(2), p. 365-373, 1999.

UETAKE,K.; HURNIK,J.F.; JOHNSON,L. Effect of music on voluntary approach of dairy cows to an automatic milking system. Applied Animal Behaviour Science, n.53, p. 175-182.

WELLS,D.L. A review of environmental enrichment for kennelled dogs, Cannis familiares. Applied Animal Behaviour Science, n.85, p. 307-317, 2004.

WOODFORD, T. The canine lullabies story. Canine Lullabies. Disponível em: < http://woodfordworld.startlogic.com/3301.html> Acesso em: 10/01/2014.6. 